\title{
PENGARUH MODEL PEMBELAJARAN PBL (PROBLEM BASED LEARNING) TERHADAP HASIL BELAJAR SISWA SMP PADA MATERI CAHAYA
}

\author{
Rofita Indri Nurcahyati ${ }^{1}$, Indrawati ${ }^{2}$, dan Iwan Wicaksono ${ }^{3}$ \\ 1,2,3 Program Studi Pendidikan IPA, Universitas Negeri Jember, Jember 68121, Indonesia \\ Corresponding author email: fitaindri98@gmail.com
}

\section{Info Artikel}

Diterima:

15 Juli 2020

Disetujui:

03 Desember 2020

Dipublikasikan:

15 Desember 2020

\begin{abstract}
Abstrak:
Penelitian ini bertujuan untuk mengkaji pengaruh model pembelajara PBL terhadap hasil belajar siswa pada materi cahaya. Jenis penelitian ini adalah penelitian eksperimen dengan desain post-test only control group design. Penelitian ini dilaksanakan di SMPN 1 Ambulu. Populasi penelitian adalah seluruh kelas VIII SMPN 1 Ambulu, pengambilan sampel menggunakan uji homogenitas. Data hasil belajar siswa dikumpulkan dengan menggunakan soal post-test dan dianalisis dengan menggunakan uji Independent Sampe T-test dengan taraf signifikansi 5\%. Hasil analisa data pada uji normalitas Kolmogorov Smirnov menunjukkan bahwa kedua sampel penelitian terdistribusi normal, sehingga selanjutnya uji statistik parametrik yakni uji Independent Sample T-test. Hasil analisa dengan uji Independent Sample T-test menunjukkan bahwa terdapat pengaruh yang signifikan model pembelajaran PBL terhadap hasil belajar siswa pada materi cahaya.
\end{abstract}

Kata kunci: Problem based learning, hasil belajar, cahaya.

\begin{abstract}
:
This study aims to examine the effect of PBL learning models on student learning outcomes in light material. This type of research is an experimental study with a post-test only control group design. This research was conducted at SMPN 1 Ambulu. The study population was all class VIII SMPN 1 Ambulu, sampling using a homogeneity test. Student learning outcomes data were collected using post-test questions and analyzed using the Independent Sampe T-test with a significance level of $5 \%$. The results of data analysis on the Kolmogorov Smirnov normality test showed that the two study samples were normally distributed, so that the parametric statistical test was then the Independent Sample T-test. The results of the analysis with the Independent Sample T-test show that there is a significant influence on the PBL learning model on student learning outcomes in light material.
\end{abstract}

Keywords: Problem based learning, light, learning outcomes 


\section{Pendahuluan}

Ilmu pengetahuan Alam (IPA) merupakan ilmu yang mempelajari fenomena-fenomena alam yang didapatkan melalui proses pengamatan yang dialakukan secara tepat dengan menggunakan prosedur yang telah disediakan dan dideskripsikan sehingga mendapatkan suatu kesimpulan yang logis dan masuk akal (Nasir et al., 2019). Menurut Budiastra et al (2019), IPA merupakan studi tentang kondisi dan peristiwa di alam secara sistematis melalui pengamatan dan eksperimen untuk menemukan fakta, konsep, proses penemuan dan sikap ilmiah yang lahir dan berkembang lewat langkah-langkah observasi, perumusan masalah, penyusunan hipotesis, pengujian hipotesis melalui eksperimen, penarikan kesimpulan, serta penemuan teori dan konsep. Dalam satuan pendidikan, pembelajaran IPA sangat ditekankan pada pemberian pengalaman belajar secara langsung agar siswa mampu mengembangkan kompetensi yang dimiliki dengan harapan seua siswa dapat memahami isi alam sekitar secara ilmiah (Trianto, 2007). Sari et al (2017) menambahkan bahwa pembelajaran IPA dapat menumbuh kembangkan kemampuan berfikir rasional, analisis dan kritis. Agar tercapainya tujuan pembelajaran IPA yang sesuai dengan uraian di atas, maka dibutuhkan kurikulum yang tepat untuk mendukung proses pembelajaran tersebut.

Saat ini, kurikulum yang sedang digunakan adalah kurikulum 2013. Dimana dalam kurikulum 2013 ini menuntut proses pembelajaran IPA menggunakan pendekatan ilmiah (scientific approach). Pendekatan saintifik merupakan pendekatan yang mendorong siswa untuk mampu memahami, menerapkan dan mengembangkan pola pikir yang rasional. Dalam kurikulum 2013, aktivitas pendekatan saintifik meliputi mengamati, menanya, mencoba, mengolah,menyaji, menalar, dan mencipta (Utami dan Murti, 2018) atau yang saat ini lebih dikenal dengan sebutan 5M. Salah satu kriteria dalam pendekatan saintifik adalah proses pembelajaran secara langsung dengan menerapkan materi pembelajaran yang berbasis pada fakta dan fenomena nyata.

Berdasarkan keadaan saat ini, pembelajaran secara langsung yang menghadapkan siswa pada fenomena nyata dalam pembelajaran IPA masih kurang. Salah satu materi pada pembelajaran IPA di SMP yang menghubungkan antara konsep-konsep dengan fenomena nyata adalah materi cahaya. Selama ini siswa mengalami kesulitan dalam hal membedakan suatu sifat bayangan, yakni sifat bayangan maya dan nyata yang terbentuk khususnya pada cermin dan lensa. Dalam mengatasi masalah tersebut, biasanya siswa akan mencoba untuk menghafal setiap bayangan yang terbentuk, sedangkan pembelajaran yang diinginkan bukanlah seperti demikian. Pembelajaran yang diharapkan adalah siswa mampu untuk memahami semua sifat cahaya baik maya maupun nyata pada cahaya dan cermin bukan hanya sekedar menghafal. Agar tercapainya tujuan yang diinginkan, alangkah lebih baik jika siswa melihat dan mengamati secara langsung proses terjadinya pembentukan bayangan, melalui percobaan (eksperimen). Disisi lain, sebagian besar guru IPA masih menerapkan pembelajaran konvensional yang berpusat pada guru (Teacher Center Learning) bukan siswa sebagai pusat pembelajaran (Student Center Learning). Hal demikian tentu akan berdampak pada hasil belajar siswa. Seharusnya ada model pembelajaran yang mampu mengembangkan pengalaman siswa tentang permasalahan IPA yang dapat meningkatkan hasil belajar siswa.

Hasil belajar adalah suatu proses yang terjadi pada seseorang guna memperoleh suatu perubahan tingkah laku baru secara menyeluruh sebagai hasil pengalaman sendiri atau interaksi dengan lingkungannya (Winarno, 2012). Hasil belajar merupakan faktor yang sangat penting dalam dunia pendidikan, hal ini dikarenakan dalam hasil belajarlah kemampuan kognitif yang diajarkan oleh guru dapat terlihat. Hasil belajar yang dicapai siswa dapat dipengaruhi oleh dua faktor, yaitu fakor internal dan fakor eksternal faktor internal bersifat biologis, sedangkan faktor eksternal antara lain adalah faktor keluarga, sekolah, dan masyarakat. Salah satu faktor eksternal yang mempengaruhi hasil belajar siswa adalah lingkungan belajar dimana didalamnya terdapat kualitas pengajaran yang tentunya mempengaruhi tinggi rendahnya atau efektif tidaknya suatu proses pembelajaran dalam mencapai tujuan pengajaran (Purwanto, 2002: 107). Salah satu usaha yang dapat dilakukan agar peserta didik memiliki hasil belajar yang baik yaitu melalui penggunaan model pembelajaran.

Model pembelajaran merupakan teknis sistematis yang dibutuhkan oleh guru agar proses pembelajaran yang sesuai untuk mengajar dan mendidik peserta didik dapat tercapai. Model pembelajaran PBL (Problem Based Learning) merupakan salah satu model pembelajaran yang menuntut akivitas siswa untuk memahami suatu konsep pembelajaran melalui situasi dan masalah yang disajikan pada awal pembelajaran dengan tujuan untuk melatih siswa menyelesaikan masalah Pengaruh Model Pembelajaran .... (Rofita Indri Nurcahyati, dkk) hal:72-78 
dengan menggunakan pendekatan pemecahan masalah (Kono et al., 2016). Sehingga, dengan digunakannya model PBL ini siswa diharapkan dapat memiliki kemampuan berpikir kritis ketika guru memberikan masalah. Siregar (2011) mengatakan bahwa model pembelajaran PBL adalah model pembelajaran yang perpusat pada teori konstruktivisme, dan berorientasi dalam proses pembelajaran siswa (Student Centered Learning). Secara sistematis model pembelajaran ini dimulai dengan proses pemecahan suatu masalah, kemudian siswa akan mampu menemukan konsep-konsep dan pengalaman secara langsung yang akan ditemukan sendiri, sehingga hal ini akan membuat siswa merasa termotivasi untuk mengikuti pembelajaran IPA.

Beberapa penelitian menunjukkan bahwa model pembelajaran PBL mampu meningkatkan hasil belajar dan menumbuhkan keterampilan berpikir kritis siswa. Hasil penelitian yang dilakukan oleh Utami et al., (2018), membuktikan bahwa model pembelajaran PBL berpengaruh signifikan dalam meningkatkan hasil belajar siswa SMK. Penelitian lain yang dilakukan oleh Kusnandar (2019) yakni ia menyatakan bahwa model pembelajaran PBL dapat meningkatkan hasil belajar dan motivasi siswa dalam pembelajaran ditandai dengan rata-rata hasil belajar siswa MTs berada pada kategori sangat tinggi dibandingkan dengan model pembelajaran konvensional.

Pada tingkat SMP, model pembelajaran PBL tidak dapat dilakukan secara murni. Peran guru sangat diperlukan untuk mendukung berjalannya sintaks model pembelajaran PBL. Hal ini sejalan dengan penelitian Susanti et al (2019), bahwa pada awal pertemuan siswa yang diberikan treatment model pembelajaran PBL mengalami beberapa kesulitan dalam mengerjakan LKS. Namun, dengan adanya bimbingan dari guru mereka dapat memahaminya. Hal ini dikarenakan siswa belum terbiasa dengan proses pembelajaran dimana mereka dituntut untuk dapat memahami konsep melalui permasalahan yang diberikan.

Berdasarkan pemaparan latar belakang di atas, untuk membuktikan apakah model pembelajaran PBL pada materi cahaya berdampak pada hasil belajar dan keterampilan berpikir kritis siswa, maka perlu dilakukan uji coba melalui penelitian eksperimen dengan judul "Pengaruh Model Pembelajaran PBL (Problem Based Learning) Terhadap Hasil Belajar Siswa SMP Pada Materi Cahaya".

\section{Metode Penelitian}

Penelitian ini merupakan penelitian eksperimen. Penelitian ini dilaksanakan di SMPN 1 Ambulu pada tanggal 3 sampai dengan 12 Maret 2020. Tujuan dari penelitian ini adalah untuk mengkaji pengaruh model pembelajaran PBL terhadap hasil belajar siswa SMP pada materi cahaya. Penelitian ini menggunakan desain post-test only control group design seperti gambar di bawah ini:

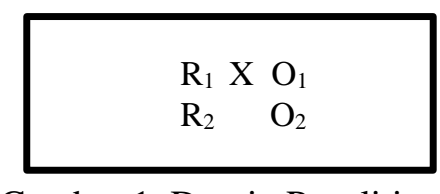

Gambar 1. Desain Penelitian

Pada desain ini, terdapat dua kelas yang masing-masing dipilih secara random (R). Kelompok yang pertama diberi perlakuan $(\mathrm{X})$ yaitu pembelajaran dengan menggunakan model pembelajaran PBL dan kelompok yang lain tidak. Selanjutnya siswa diberi post-test $\left(\mathrm{O}_{1}: \mathrm{O}_{2}\right)$ untuk mengetahui ada tidaknya pengaruh model PBL terhadap hasil belajar siswa.

Populasi dalam penelitian ini adalah seluruh siswa kelas VIII SMPN 1 Ambulu. Selanjutnya, untuk pengambilan sampel penelitian dilakukan menggunakan uji homogenitas dengan metode cluster random sampling (acak). Berdasarkan hasil uji homogenitas, kelas yang terpilih menjadi sampel penelitiaan adalah kelas VIII A sebagai kelas eksperimen dan kelas VIII I sebagai kelas kontrol. Sehingga, untuk kelas eksperimen diberikan perlakuan dengan menggunakan model pembelajaran PBL, sedangkan untuk kelas kontrol tidak diberi perlakuan dengan menggunakan model pembelajaran PBL. Untuk kelas kontrol perlakuan yang diberikan adalah dengan menggunakan model pembelajaran yang biasa digunakan oleh guru saat proses pembelajaran.

Data hasil belajar dikumpulkan melalui post-test. Adapun cara perhitungan nilai persentase hasil belajar siswa sebagai berikut:

$$
P_{h b}=\frac{P}{N} \times 100 \%
$$


Keterangan:

$P_{h b} \quad=$ Persentase penilaian hasil belajar

$\mathrm{P} \quad=$ Jumlah skor yang diperoleh.

$\mathrm{N} \quad=$ Jumlah skor maksimum

Selanjutnya, akan dilakukan uji normalitas dengan menggunakan uji Kolmogorov Smirnov dengan bantuan software SPSS 22. Pada uji Kolmogorov Smirnov, jika data terdistribusi normal, maka akan dilanjutkan dengan uji hipotesis dengan uji Independent Sample T-test.

\section{Hasil Penelitian dan Pembahasan}

Dalam penelitian ini, langkah aawal yang dilakukan adalah melakukan uji homogenitas terhadap semua populasi penelitian. Hal ini dilakukan untuk mengetahui apakah kemampuan seluruh siswa SMPN 1 Ambulu bersifat homogen atau tidak. Uji homogenitas dilakukan dengan menggunakan nilai menggunakan nilai ujian akhir semester. Data uji homogenitas dengan menggunakan SPSS 22 dapat dilihat pada tabel di bawah ini:

Tabel 1. Uji Homogenitas

\begin{tabular}{|c|c|c|c|}
\hline Levene Statistic & df1 & df2 & Sig. \\
\hline .917 & & 274 & .503 \\
\hline
\end{tabular}

Berdasarkan tabel 1 tersebut, dapat dilihat bahwa nilai Sig. menunjukkan nilai sebesar 0,503 dengan taraf signifikansi 0,05 yang artinya 0,503 >0,05. Hal ini menunjukkan bahwa seluruh siswa kelas VIII SMPN 1 Ambulu memiliki kemampuan yang homogen setelah diketahui bersifat homogen. Selanjutnya dilakukanlah teknik cluster random sampling dengan menggunakan undian sehingga ditetapkan kelas VIII A sebagai kelas eksperimen dan kelas VIII I sebagai kelas kontrol.

Dalam penelitian ini, hasil belajar yang diukur adalah hasil belajar dalam ranah kognitif. Data hasil belajar pada penelitian ini diperoleh melalui pemberian soal post-test. Adapun rekapitulasi data pada nilai posttest hasil belajar siswa pada kelas eksperimen dan kelas kontrol dapat dilihat pada Tabel 2 berikut.

Tabel 2. Rekapitulasi nilai post-test hasil belajar

\begin{tabular}{ccc}
\hline \multirow{2}{*}{ Komponen } & \multicolumn{2}{c}{ Kelas } \\
\cline { 2 - 3 } & Eksperimen & Kontrol \\
\hline Jumlah Siswa & 31 & 31 \\
Nilai tertinggi & 85 & 80 \\
Nilai terendah & 60 & 35 \\
Rata-rata & 72,25 & 56,45 \\
\hline
\end{tabular}

Perbandingan nilai post-test kelas eksperimen dan kelas kontrol tersebut dapat dilihat lebih jelas pada grafik di bawah ini.

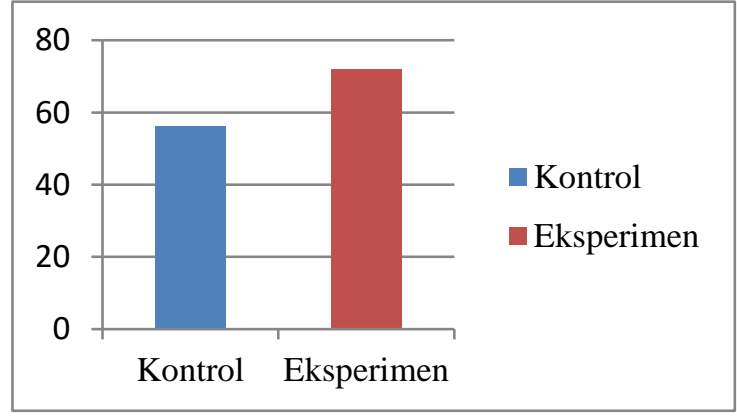

Gambar 2. Rata-rata nilai post-test

Pengaruh Model Pembelajaran .... (Rofita Indri Nurcahyati, dkk) hal:72-78 
Berdasarkan Tabel 3.2 dan gambar 3.1 terlihat bahwa nilai rata-rata post-test hasil belajar siswa kelas eksperimen lebih tinggi dibandingkan dengan nilai rata-rata post-test kelas kontrol. Rata-rata skor yang diperoleh kelas eksperimen sebesar 72,25 sedangkan kelas kontrol sebesar 56,45. Kemudian, untuk mengkaji hasil belajar siswa menggunakan model pembelajaran PBL dengan siswa yang menggunakan model pembelajaran konvensional yang diterapkan guru dengan menggunakan uji Independent Sample T-Test dengan menggunakan SPSS 22.

Sebelum menguji pengaruh model pembelajaran PBL perlu dilakukan uji normalitas terlebih dahulu untuk mengetahui bahwa data tersebut terdistribusi normal atau tidak. Uji normalitas yang digunakan yakni menggunakan uji Kormogorov-Smirnov. Hasil uji normalitas data hasil belajar sacara lengkap dapat dilihat pada Tabel 3 berikut:

Tabel 3. Hasil Uji Normalitas

\begin{tabular}{|c|c|c|c|}
\hline \multicolumn{4}{|c|}{ One-Sample Kolmogorov-Smirnov Test } \\
\hline & & Kontrol & Eksperimen \\
\hline $\mathrm{N}$ & & 31 & 31 \\
\hline \multirow[t]{2}{*}{ Normal Parameters ${ }^{\mathrm{a}, \mathrm{b}}$} & Mean & 56.4516 & 72.2581 \\
\hline & $\begin{array}{l}\text { Std. } \\
\text { Deviation }\end{array}$ & 12.12391 & 8.25012 \\
\hline Most Extreme & Absolute & .122 & .124 \\
\hline \multirow[t]{2}{*}{ Differences } & Positive & .122 & .124 \\
\hline & Negative & -.114 & -.114 \\
\hline Test Statistic & & .122 & .124 \\
\hline Asymp. Sig. (2-tailed) & & .200 & .200 \\
\hline
\end{tabular}

a. Test distribution is Normal.

b. Calculated from data.

Berdasarkan tabel 4.3 hasil uji normalitas pada tabel One-Sample Kolmogorov-Smirnov Test, pada nilai Asymp. Sig. (2-tailed) untuk kelas eksperimen dan kontrol diperoleh nilai sebesar 0,200. Nilai Asymp. Sig. (2-tailed) yang dihasilkan lebih besar dari nilai $\alpha(0,05)$. Sehingga jika disesuaikan dengan pedoman pengambilan keputusan, maka dapat disimpulkan kelompok data di atas terdistribusi normal, sehingga untuk menguji hipotesis statistik dapat dilakukan dengan menggunakan uji Independent Sample T-Test.

Hasil pengujian hipotesis statistik ini dilakkukan dengan menggunakan uji Independent Sample T-Test dan hasil secara menyeluruh dapat dilihat pada lampiran D2. Adapun analisis nilai uji Independent Sample T-Test dapat dilihat pada Tabel 4. Berdasarkan hasil uji Independent Sample TTest pada tabel di atas, diketahui bahwa nilai Sig. (2-tailed) pada kelas eksperimen dan kelas kontrol sebesar 0,000. Pengujian hipotesis yang digunakan adalah uji pihak kanan, maka nilai Sig. (2-tailed) sebesar 0 dibagi 2 didapatkan nilai Sig. (1-tailed) yakni sebesar 0 . Nilai $0<0,05$ sehingga $\mathrm{H}_{\mathrm{a}}$ diterima dan $\mathrm{H}_{\mathrm{o}}$ ditolak. Kemudian dapat dinyatakan bahwa nilai rata-rata hasil belajar kelas eksperimen lebih besar dari kelas kontrol. Berdasarkan hasil pengujian dapat disimpulkan bahwa model pembelajaran PBL berpengaruh signfikan terhadap hasil belajar siswa SMP pada materi cahaya, dalam hal ini menunjukkan kelas Eksperimen VIII A memiliki rata-rata hasil belajar lebih baik dari kelas kontrol VIII I.

Tujuan penelitian dalam penelitian ini adalah mengkaji pengaruh model pembelajaran PBL terhadap hasil belajar siswa. Hasil belajar siswa diperoleh melalui data hasil skor post-test yang telah dilakukan pada kelas kontrol maupun kelas eksperimen. Pada soal post-test, diwakili oleh 20 (dua puluh) butir soal dengan tiap indikator terdiri dari soal pilihan ganda. 
Tabel 4. Hasil Uji Independent Sample T-test

\begin{tabular}{|c|c|c|c|c|c|c|c|c|c|c|}
\hline & & \multicolumn{2}{|c|}{$\begin{array}{l}\text { Levene's } \\
\text { Test for } \\
\text { Equality of } \\
\text { Variances }\end{array}$} & \multicolumn{7}{|c|}{ t-test for Equality of Means } \\
\hline & & \multirow[b]{2}{*}{$\mathrm{F}$} & \multirow[b]{2}{*}{ Sig. } & \multirow[b]{2}{*}{$\mathrm{t}$} & \multirow[b]{2}{*}{ df } & \multirow{2}{*}{$\begin{array}{l}\text { Sig. } \\
(2- \\
\text { tailed } \\
\quad)\end{array}$} & \multirow{2}{*}{$\begin{array}{c}\text { Mean } \\
\text { Differenc } \\
\mathrm{e} \\
\end{array}$} & \multirow{2}{*}{$\begin{array}{c}\text { Std. } \\
\text { Error } \\
\text { Differen } \\
\text { ce }\end{array}$} & \multicolumn{2}{|c|}{$\begin{array}{l}\text { 95\% Confidence } \\
\text { Interval of the } \\
\text { Difference }\end{array}$} \\
\hline & & & & & & & & & Lower & Upper \\
\hline \multirow[t]{2}{*}{ Nilai } & $\begin{array}{l}\text { Equal } \\
\text { variances } \\
\text { assumed }\end{array}$ & 5.943 & .318 & -6.001 & 60 & .000 & -15.80645 & 2.63386 & -21.07496 & -10.53795 \\
\hline & $\begin{array}{l}\text { Equal } \\
\text { variances } \\
\text { not } \\
\text { assumed }\end{array}$ & & & -6.001 & $\begin{array}{r}52.8 \\
78\end{array}$ & .000 & -15.80645 & 2.63386 & -21.08959 & -10.52331 \\
\hline
\end{tabular}

Berdasarkan data akumulasi post-test, nilai rata-rata post-test dari kelas eksperimen adalah sebesar 72,25, sedangkan untuk nilai rata-rata post-test kelas kontrol adalah sebesar 56,45. Dari data tersebut dapat dilihat bahwa nilai rata-rata post-test kelas eksperimen lebih tinggi dibandingkan dengan nilai rata-rata post-test kelas kontrol. Hal ini disebabkan hasil belajar siswa dapat meningkat dikarenakan penggunaan model pembelajaran PBL yang telah diberikan kepada kelas eksperimen. Siswa lebih memahami materi yang sedang dipelajari karena adanya permasalahan dan beberapa eksperimen yang telah siswa lakukan. Sehingga apabila siswa dapat memahami semua materi yang tehah diajarkan, tentu akan berdampak terhadap nilai hasil belajar siswa pada kelas eksperimen. Berdasarkan pada hasil uji Independent Sample T-test dengan menggunakan bantuan SPSS 22, menunjukkan bahwa hasil belajar kelas eksperimen lebih baik dibandingkan kelas kontrol. Berdasarkan hasil tersebut, maka hipotesis dalam penelitian ini dapat diterima dan dapat disimpulkan bahwa model pembelajaran PBL berpengaruh signifikan terhadap hasil belajar siswa SMP pada materi cahaya.

Peneltian ini sejalan dengan penelitian yang telah dilakukan oleh Kusnandar (2019) yang menyatakan bahwa model pembelajaran PBL ini dapat meningkatkan hasil belajar kognitif siswa. Ningsih, et al, (2019) juga menyatakan bahwa hasil belajar kognitif siswa mengalami peningkatan setelah guru menggunakan model pembelajaran PBL. Selanjutnya penelitian yang dilakukan oleh Lagiono (2019) menyatakan bahwa dengan menggunakan model pembelajaran PBL dapat meningkatkan hasil belajar kognitif siswa di kelas eksperimen sebesar 81, 48\% sedangkan pada kelas kontrol sebesar 77,35\%. Hal tersebut juga didukung oleh penelitian yang telah dilakukan oleh Furqan, et al., (2019) menyatakan bahwa terdapat pengaruh signifikan penggunaan model pembelajaran PBL terhadap hasil belajar siswa yang ditunjukkan dengan rata-rata nilai post-test hasil belajar kelas eksperimen lebih tinggi dibandingkan dengan kelas kontrol. Berdasarkan penelitian yang telah dilakukan dan hasil pengujian, dapat disimpulkan bahwa model pembelajaran PBL berpengaruh signfikan terhadap hasil belajar siswa SMP pada materi cahaya. 


\section{Simpulan}

Berdasarkan hasil penelitian di atas, dapat disimpulkan bahwa model pembelajaran PBL (Problem Based Learning) berpengaruh signifikan terhadap hasil belajar siswa kelas VIII A SMPN 1 Ambulu pada materi cahaya. Hal ini dibuktikan dengan nilai signifikan $(\alpha)$ pada data hasil belajar siswa diperoleh sebesar 0. Berdasarkan pedoman pengambilan keputusan, jika nilai Sig. (1-tailed) $\leq$ 0.05 , maka $\mathrm{H}_{0}$ ditolak dan $\mathrm{H}_{\mathrm{a}}$ diterima. Sehingga dapat disimpulkan bahwa model pembelajaran PBL (Problem Based Learning) berpengaruh signifikan terhadap hasil belajar siswa kelas VIII A SMPN 1 Ambulu pada materi cahaya.

\section{Referensi}

Budiastra, A. K., N. Erlina, dan I. Wicaksono. 2019. The Factors Affecting Teachers' Readiness In Developing Science Concept Assessment Through Inquiry-Based Learning Process In Elementary Schools. Advances in Social Sciences Research Journal. 6(9): 355-366.

Kono, R., Mamu, H., dan Tangge, L. 2016. Pengaruh Model Problem Based Learning (PBL) Terhadap Pemahaman Konsep Biologi Dan Keterampilan Berpikir Kritis Siswa Tentang Ekosistem Dan Lingkungan Di Kelas X SMA Negeri 1 Sigi. Jurnal Sains dan Teknologi Tadulako. 5(1): 28-38.

Kusnandar, D. 2019. Pengaruh Model Problem Based Learning Terhadap Hasil Belajar Kognitif Dan Motivasi Belajar IPA. Jurnal Pendidikan Islam, Sains, Sosial, dan Budaya. 1(1): 15-26.

Nasir, M., Nurcaya dan M. Nur. 2019. Pendampingan Musyawarah Guru Mata Pelajaran (MGMP) IPA SMP Untuk Mengembangkan Perangkat Pembelajaran Berbasis Potensi Lokal Di Kabupaten Wajo. Sinar Sang Surya: Jurnal Pusat Pengabdian Kepada Masyarakat. 2(2): 1-8.

Purwanto, M.,N. 2002. Psikologi Pendidikan. Bandung: Remadja Rosdakarya.

Sari, S. M., Indrawati dan R. D. Handayani. 2017. Pengaruh Model Pembelajaran PBL (Problem Based Learning) Terhadap Keterampilan Proses dan Hasil Belajar Siswa dalam Pembelajaran Fisika di SMP. Jurnal Pembelajaran Fisika, 5(2): 103-108.

Siregar, S. B. 2019. Penerapan Model Problem Based Learning (PBL) Untuk Meningkatkan Hasil Belajar Kimia Siswa Kelas XII MIPA 5 SMA Negeri 17 Bandung. Jurnal Ilmiah Indonesia. 4(9): 132-140.

Susanti, D., H. B. Said dan Relawati, R. 2019. Perbandingan Kemampuan Pemahaman Konsep Matematis Melalui Model Pembelajaran Take And Give dan Model Pembelajaran Problem Based Learning (PBL) pada Siswa Kelas VIII SMP Negeri 11 Kota Jambi. Jurnal Pendidikan Matematika, 3(1): 17-20.

Trianto. 2007. Model Pembelajaran Terpadu Dalam Teori dan Praktek. Jakarta: Prestasi Pustaka.

Utami, A. U dan Murti, S. C. C. 2019. Peningkatan Literasi Sains Melalui Pembelajaran Berbasis Scientific Approach. EDUSCIENCE. 1(1): 50-54.

Utami, T. S., D. Santi, dan A. R. Suparman. 2018. Pengaruh Model Pembelajaran Problem Based Learning (PBL) Terhadap Hasil Belajar Kognitif Peserta Didik Kelas XI SMK Negeri 02 Manokwari. Arfak Chem: Chemistry Education Journal. 1(1), 21-26.

Winarno, B. 2012. Pengaruh Lingkungan Belajar dan Motivasi Berprestasi Terhadap Hasil Belajar Siswa Kompetensi Keahlian Teknik Otomasi Industri di Sekolah Menengah Kejuruan Negeri 2 Depok Yogyakarta. Jurnal Skripsi. Yogyakarta: Fakultas Teknik Universiras Negeri Yogyakarta. 